\title{
La construcción mediática del colectivo LGTB+ en el cine blockbuster de Hollywood. El uso del pinkwashing y el queerbaiting
}

\author{
The media construction of LGBT + characters in Hollywood \\ blockbuster movies. The use of pinkwashing and queerbaiting
}

Juan-José Sánchez-Soriano. Universidad de Murcia. España.

juanjose.sanchez4@um.es

$[\mathrm{CV}]$ (1) $\mathrm{C}$

Leonarda García-Jiménez. Universidad de Murcia. España. Colorado State University. EE.UU.

leonardagj@um.es

$[\mathrm{CV}]$ (1) $\mathrm{G}$

Investigación financiada: Este artículo es producto del contrato predoctoral FPU 15/04411, financiado por el Ministerio de Educación, Cultura y Deporte de España. https://www.educacionyfp.gob.es/servicios-alciudadano-mecd/catalogo/general/educacion/998758/ficha/998758-2015.html

Fechas:

- inicio del contrato de investigación: 01/05/2017

- término del contrato de investigación: 01/05/2021

Cómo citar este artículo / Referencia normalizada

Sánchez-Soriano, J. J. y García-Jiménez, L. (2020). La construcción mediática del colectivo LGTB+ en el cine blockbuster de Hollywood. El uso del pinkwashing y el queerbaiting. Revista Latina de Comunicación Social, (77), 95-116. https://www.doi.org/10.4185/RLCS-2020-1451

\section{RESUMEN}

Introducción: El pinkwashing y queerbaiting son estrategias de marketing utilizadas por las grandes productoras de cine de Hollywood para ser percibidas como industrias tolerantes con respecto a la diversidad sexual y así atraer a audiencias LGTB+. Su objetivo es limpiar su imagen ante acciones negativas, como las denuncias que desde 2013 viene haciendo la asociación GLAAD en sus informes anuales debido a la falta de diversidad sexual en los largometrajes tipo blockbuster. Metodología: Las películas que conforman la muestra son: Black Panther, Jurassic World: El reino caído, Star Wars: Los últimos Jedi, Thor: Ragnarok_y La bella y la bestia. Para su estudio se ha utilizado un análisis crítico del discurso (ACD). Resultados: Estos largometrajes, en los que se eliminó cualquier mención explícita a la diversidad sexual a pesar de haber sido promocionados como "gay friendly", contaron con una participación muy reducida de personajes LGTB+, quienes fueron presentados mayoritariamente de manera estereotipada y como antítesis del héroe/heroína heterosexual. Discusión y conclusiones: A pesar de publicitar la inclusión de personajes LGTB+ durante la campaña de promoción, estos largometrajes se enmarcan en la lógica heteronormativa y eliminan referencias explícitas a la diversidad sexual para evitar las posibles pérdidas económicas. 
PALABRAS CLAVE: pinkwashing; queerbating; cine; LGTBI; Hollywood; análisis crítico del discurso.

\begin{abstract}
Introduction: Pinkwashing and queerbaiting are marketing strategies used by major Hollywood film producers to be perceived as tolerant industries regarding sexual diversity and thus to attract LGBT+ audiences. Its objective is to clean up its image in the face of negative actions, such as the complaints that the GLAAD association has been making in its annual reports since 2013 due to the lack of sexual diversity in blockbuster-type feature films. Methodology: The films that make up the sample are: Black Panther, Jurassic World: The Fallen Kingdom, Star Wars: The Last Jedi, Thor: Ragnarok, and Beauty and the Beast. For its study a critical discourse analysis (CDA) has been used. Results: These feature films, in which any explicit mention of sexual diversity was eliminated despite having been promoted as "gay friendly", had a very limited participation of LGBT+ characters, who were presented in a stereotypical way and as an antithesis of the straight hero/heroin. Discussion and conclusions: Despite advertising the inclusion of LGBT + characters during the promotional campaign, these feature films are framed in heteronormative logic and eliminate explicit references to sexual diversity to avoid possible economic losses.
\end{abstract}

KEYWORDS: pinkwashing; queerbaiting; films; LGBTI; Hollywood; critical discourse analysis.

\title{
CONTENIDOS
}

1. Introducción. 1.1. Pinkwashing y queerbaiting como técnicas de mantenimiento de la heteronormatividad cinematográfica. 1.2. Análisis crítico del discurso y su papel en la denuncia de las construcciones y representaciones desiguales. 1.3. Colectivo LGTB + y representación en el cine de Hollywood: breve repaso histórico. 2. Metodología. 3. Resultados. 3.1. Resultados del análisis de las entrevistas y elementos promocionales previos al estreno del blockbuster. 3.2. Resultados a nivel macro: los discursos sobre los colectivos LGTB+. 3.3. Resultados a nivel micro: la construcción de los personajes LGTB+, sus contextos y perspectivas. 3.3.1. Lexicalización. 3.3.2. Estructuras proposicionales y focus. 4. Discusión. 5. Conclusiones. 6. Bibliografía.

\section{Introducción}

Ante las críticas por la escasa presencia o por las representaciones tradicionalmente estereotipadas sobre el colectivo LGTB+ (Lesbianas, Gais, Transexuales, Bisexuales y más identidades, como Intersexuales o Queer, entre otras), en los últimos años se ha producido una tendencia a promocionar la inclusión de personajes o tramas del colectivo en los largometrajes creados por las grandes productoras, o majors, de Hollywood (Walt Disney Pictures, Warner Bros o Sony Pictures, entre otras) como manera de crear una visión positiva y tolerante hacia los derechos de las minorías. Esta aparente preocupación e inclusión de enfoques positivos sobre las diversas orientaciones sexuales ha tenido lugar en algunos de los blockbusters más importantes estrenados recientemente. El concepto de blockbuster es entendido actualmente como un tipo de cine de Hollywood, principalmente, realizado y producido con enorme presupuesto, caracterizado por apelar a la emoción y por la espectacularización mediante el uso de efectos especiales. Se trata de un cine dirigido a un público mayoritario y con el que se espera recaudar una gran cantidad de dinero en las taquillas de los cines mundiales. Es, por lo tanto, un cine ubicado dentro de la lógica de la industria comercial (RubioAlcover, 2007).

Sin embargo, el informe anual de la asociación GLAAD (Gays \& Lesbians Alliance Against Defamation) sobre la representación de orientaciones sexuales diversas en el cine de Hollywood publicado en 2018, señala que en el año 2017 la representación de personajes LGTB+ en el cine 
blockbuster de Hollywood ha caído hasta mínimos históricos. De esta forma, de los 109 que fueron estrenados por los grandes estudios de Hollywood en ese año, solamente un 12,8\% (14 películas) contaba con tramas o representaciones LGTB+. Esto convierte a 2017 en el año con menor representación desde el comienzo de estos análisis por parte de la asociación. Por otro lado, de estas 14 representaciones, solo 7 personajes aparecían en escena más de cinco minutos en el total. El estudio, además, encontró que el 57\% de los personajes LGTB+ no compartían los rasgos caucásicos blancos tradicionales de Hollywood (GLAAD, 2018). Por lo tanto, esta investigación parte de la necesidad de profundizar y analizar la desconexión entre la promoción de los estudios de Hollywood de inclusión de elementos LGTB $+\mathrm{y}$, a la vez, el descenso cuantitativo del número de representaciones.

Por otro lado, este cine blockbuster proveniente de Hollywood cuenta con una amplia hegemonía en las salas de cine mundiales, ya que de sus productoras surge el $80 \%$ del total de los largometrajes que son proyectados en nuestras pantallas (Pardo, 2011). De esta manera, si corrientes y teorías históricas como los estudios culturales han analizado la enorme importancia e influencia de los elementos audiovisuales y de sus representaciones en la sociedad, la investigación queda justificada de la misma manera por conocer, de forma novedosa, el estado de este cine actual de gran presupuesto y dirigido a un gran público y cuáles y cómo son los discursos creados sobre las minorías sociales, en este caso, el colectivo LGTB+.

Por lo tanto, y partiendo de la anterior premisa, el primer objetivo de esta investigación es conocer de forma crítica cómo es la construcción discursiva del colectivo LGTB+ en los blockbusters de Hollywood actuales. El segundo objetivo es analizar si las majors han utilizado las técnicas del pinkwashing y el queerbaiting para mostrar una falsa visión progresista sobre sí mismos que pudiera beneficiarles socialmente, pero sin incluir de facto enfoques propios de la diversidad sexual que provoquen las protestas del público conservador con las consiguientes pérdidas económicas.

\subsection{Pinkwashing y queerbaiting como técnicas de mantenimiento de la heteronormatividad cinematográfica}

El concepto pinkwashing, o "lavado de imagen rosa", ha sido tratado desde diversas disciplinas, como la economía o la comunicación, pero han sido las ciencias políticas, con autoras como Spade (2015), las que lo han analizado más ampliamente. Este análisis se ha centrado principalmente en el caso de Israel y sus maniobras para proyectar una imagen favorable y amigable hacia el colectivo LGTB + a través de medidas legislativas, políticas y sociales. Estas medidas han tenido la finalidad de contrarrestar las críticas e imagen negativa debido a la guerra mantenida con Palestina, pretendiendo con ello proyectar una imagen de sí mismos como progresistas, lo que les ayudaría potencialmente a mejorar sus relaciones internacionales con el resto de los estados y naciones y el poder atraer a un mayor número de turistas del colectivo a su país (Puar, 2013).

De igual manera, el pinkwashing, entendido como un uso de técnicas de marketing para obtener beneficios (políticos, sociales o económicos, entre otros), a pesar de ser un ámbito menos estudiado, es usado no solo por los estados sino por otras instituciones, productos, personas o productoras de cine, para mostrar una imagen de apertura hacia el colectivo LGTB+ con la intención de distraer la atención de aquellos aspectos negativos por los que tradicionalmente han sido criticados: guerras con otros países por parte de Israel o el mantenimiento de representaciones estereotipadas sobre género y orientación sexual en el caso de Hollywood.

El pinkwashing se encuentra además relacionado con otros conceptos como el purplewashing, basado en el conjunto de estrategias tomadas para adoptar la apariencia de apoyo al movimiento 
feminista. Este término, popularizado por autoras como Vasallo (2013), es utilizado igualmente por las productoras de cine, como en el caso del reciente blockbuster Capitana Marvel (Marvel Studios, 2019), sobre una de las primeras mujeres superheroínas protagonista de un largometraje, que ha sido promocionado y estrenado haciéndolo coincidir con las reivindicaciones feministas del día 8 de marzo de 2019.

Por otro lado, el queerbaiting, término popularizado por el fandom y los fenómenos fan, se encuentra en amplia relación con el pinkwashing y se basa en las técnicas usadas en la amplia gama de productos culturales: libros, videojuegos, películas o series de ficción, entre otros, para sugerir una posible trama LGTB+ sin que esto llegue a ocurrir finalmente, lo que mantiene la representación mayoritariamente heterosexual en sus personajes (Brennan, 2018). La intención con esta técnica es atraer al potencial público del colectivo sin provocar el rechazo de la audiencia más conservadora. El motivo por el que la audiencia LGTB + o, en general, la audiencia sensibilizada hacia cuestiones de diversidad sexual se ve atraída por estos subtextos homoeróticos (simbolismo, gestos, o bromas, entre otros) es la falta de suficiente representación positiva real y no estereotipada en los largometrajes y elementos culturales, como muestra el informe GLAAD (2018).

Por lo tanto, ambos términos, pinkwashing y queerbaiting, son entendidos como una forma de abuso (Brennan, 2018) sobre las representaciones y las identidades del propio colectivo LGTB+. El cine blockbuster de Hollywood utiliza estas técnicas para mejorar su imagen a nivel social y aumentar sus beneficios dentro del sistema capitalista, pero como veremos en esta investigación, pinkwashing y queerbaiting ayudan a mantener la heteronormatividad hegemónica dentro de los productos audiovisuales y a ocultar las diversidades sexuales.

\subsection{Análisis crítico del discurso y su papel en la denuncia de las construcciones y representaciones desiguales}

El análisis crítico del discurso (o ACD) es tanto una perspectiva teórica como un método de análisis. Es una perspectiva centrada en el análisis de aquellos discursos que se encuentran basados en la producción y/o reproducción del abuso de poder y de la discriminación en la sociedad. Su foco se centra en los procesos sociales de circulación simbólica, estudiando el ejercicio de poder social ejercido por las elites, instituciones o grupos con el objetivo de mantener una desigualdad social (Pardo-Abril, 2007). Su finalidad es, por un lado, una lucha contra la desigualdad que produzca una liberación de los oprimidos contra aquellos que, basándose en su posición de poder, legitiman las injusticias y, por otro lado, generar conciencia sobre ello.

La importancia de los discursos recae en su capacidad para construir, mantener o cambiar las estructuras sociales y estos pueden provenir de diversas fuentes: la política, los medios audiovisuales, el derecho o la educación, entre otros (Van Dijk, 2002). Estos discursos, como prácticas sociales históricamente situados, están insertos en unas macro y micro estructuras (Stecher, 2009) y son capaces de significar áreas de la experiencia desde diferentes posiciones, por ejemplo, desde los discursos patriarcales o desde los discursos feministas (Fairclough, 2008).

Uno de los elementos que mantiene la relación entre discurso y sociedad se halla en el cine y la televisión, elementos de enorme poder en la socialización de los individuos y sociedades. En estos discursos es posible inferir la forma en la que se habla o se representan minorías como el colectivo LGTB+. De esta forma, un discurso cinematográfico negativo sobre este colectivo afecta en la manera en que se mantienen y forman estereotipos y prejuicios sobre ellos, y, específicamente, sobre las representaciones sociales, fomentando actitudes como la homofobia. 
El ACD como técnica es considerado diverso, heterogéneo y multidisciplinar (Stecher, 2009), sin un mismo método que pueda aplicarse por igual a todos los enfoques de las humanidades y ciencias sociales, sino que es una perspectiva crítica y una metodología que se adapta a las diferentes circunstancias y objetos de estudio (Van Dijk, 2003). Esto es debido a que tanto los discursos como las estructuras sociales son de la misma forma multidisciplinares. En el caso del colectivo LGTB+, el ACD ha sido utilizado mayoritariamente para analizar los discursos provenientes de las leyes y políticas públicas (Echevarría y Martín-Maturana, 2015) y de los discursos políticos (Stakic, 2011) y religiosos. Por ello, habría un vacío importante en el análisis mediante ACD de la construcción de personajes y tramas LGTB+ dentro del cine actual blockbuster de Hollywood.

Así, los discursos, en base al ACD, están influidos por los grupos que poseen el control sobre los modelos mentales (Van Dijk, 2003), es decir, modelos de los que aprendemos nuestro conocimiento del mundo, como son la televisión o la socialización a través de las instituciones educativas o familiares, y que se expresan mediante manifestaciones tales como las representaciones estereotipadas o los fenómenos socioculturales de ocultamiento (Pardo-Abril, 2007). Por lo tanto, más que en su componente lingüístico, el ACD se centra en la relación entre discurso, ideología, poder y sociedad, y, específicamente, en la forma en que estos ayudan a la producción y reproducción de la dominación social (Van Dijk, 2002), con el objetivo ético de descifrar y denunciar estas desigualdades para subvertirlas y deconstruirlas.

\subsection{Colectivo LGTB+ y representación en el cine de Hollywood: breve repaso histórico}

El cine de Hollywood ha estado tradicionalmente regido por una moral puritana y conservadora y prácticamente desde el principio ha contado con una censura que "evitara herir la sensibilidad de los espectadores" (Black en Durán-Manso, 2016, p. 60). Si en su origen esta censura intentó eliminar escenas violentas o con contenido sexual explícito, pronto comenzó a adentrarse en temas morales y se crearon leyes concretas para ello en los primeros años del siglo XX, como el denominado Código Hays, que contó con el apoyo y presiones por parte de la Iglesia Católica, en el que la homosexualidad era considerada una perversión sexual y no podía ser mencionada de forma directa (Durán-Manso, 2014).

Aun así, algunas películas, como la primera que sugirió la homosexualidad de los personajes, $L a$ carretera al infierno, de Rowland Brown que tuvo su estreno en 1932, consiguieron introducir breves escenas sutiles y nunca explícitas sobre un personaje secundario en un entorno carcelario. Hasta el final de los años sesenta, esta censura limitó e invisibilizó la inclusión de representaciones LGTB+. A partir de entonces, y en las siguientes décadas tras la eliminación del Código Hays, el modelo de Hollywood siguió centrado en un esquema patriarcal y las representaciones sobre homosexualidad se produjeron de forma muy breve, mediante elementos sutiles y siempre estereotipados, basadas en: la burla o comicidad, usando la conocida figura del "mariquita o sissy" (González, 2008); en la denuncia de la condición homosexual, convirtiendo a estos personajes en los villanos o inestables mentalmente; o en la trágica vida de estas personas, como en el largometraje $U n$ tranvía llamado deseo, de Tennessee Williams, en la que un personaje se suicida atormentado por su sexualidad. Todas estas imágenes, además, estaban basadas en un sistema heteropatriarcal, que premiaba la heterosexualidad promoviendo una imagen negativa sobre el colectivo LGTB + , imagen que caló entre los espectadores y que a la vez representaba a la sociedad conservadora de la época (Durán-Manso, 2016).

Esta representación estereotipada y basada en el castigo a aquellas sexualidades distintas a la heterosexual y que utilizaba al homosexual como objeto de burla (Melero, 2014), continuó en el cine de Hollywood hasta los años ochenta, a pesar del aumento progresivo en estas épocas de 
largometrajes con personajes y tramas LGTB+, coincidiendo con los crecientes movimientos sociales por los derechos homosexuales de las últimas décadas. Hay que esperar hasta los noventa, con películas como Philadelphia, de Jonathan Demme, sobre una pareja masculina en la que uno de ellos descubre ser portador del VIH, para que Hollywood apostara por grandes presupuestos y actores reconocidos para interpretar a personajes LGTB+. Aun así, se seguía manteniendo una autocensura, como el hecho de no mostrar apenas escenas afectivas o sexuales entre los personajes varones y la difusión de estereotipos, como asociar la homosexualidad con el virus del sida. No ocurrió de la misma manera en aquellos largometrajes creados por las productoras minoritarias o en las películas del denominado New Queer Cinema, alejadas del gran circuito comercial y que, por el contrario, trataron en esa época de desafiar la heteronormatividad existente en Hollywood (Smith, 2006).

En las décadas de 2000 y 2010, películas como Brokeback Mountain, de Ang Lee, sobre dos vaqueros homosexuales en un contexto rural y homófobo que obtuvo una enorme popularidad y reconocimientos en los Óscar, junto a otras como Moonlight (2017), de Barry Jenkins, sobre un joven homosexual afroamericano abocado a la marginalidad social, abrieron la puerta a representaciones LGTB+ por parte de Hollywood que eliminaran el carácter cómico de los personajes y que contaran con el apoyo de público y crítica. Otro ejemplo es Bohemian Rhapsody (2018), sobre la vida de Freddie Mercury, con nominación a mejor película y protagonizada por un personaje homosexual. Por lo tanto, hay un aumento del reconocimiento a través de premios a estos largometrajes con narrativas LGTB+. Sin embargo, todas siguen manteniendo estereotipos como el trágico final, la vida atormentada por la sexualidad o el de la lesbiana con rasgos de masculinidad tóxica, como en el caso de la película Monster (2003), de Patty Jenkins, sobre una asesina lesbiana.

Así, en los últimos años, a pesar de la inclusión de tramas más profundas y nuevas temáticas sobre personajes del colectivo LGTB + y de la eliminación de cualquier ley que restrinja la libertad de expresión, en Hollywood aún se produce una autocensura que pueda evitar las pérdidas económicas y críticas en países o sectores abiertamente conservadores de la sociedad, lo que provoca una escasa representación LGTB+. Además, se siguen manteniendo representaciones no positivas y basadas en los estereotipos establecidos en el imaginario sociocultural sobre la homosexualidad (GLAAD, 2018), como el gay amanerado, la lesbiana con rasgos de masculinidad hegemónica (Kaplan, Rosenmann y Shuhendler, 2017) o el final trágico de los personajes.

\section{Metodología}

En base a la literatura científica revisada, esta investigación parte de las siguientes hipótesis:

H1: Los grandes estudios de Hollywood utilizan las técnicas del pinkwashing y el queerbaiting para potenciar una imagen progresista de sí mismos, pero esta publicidad no se corresponde con una construcción real, positiva y normalizada de personajes LGTB+ en los largometrajes actuales.

H2: Las escasas representaciones se encuentran, además, estereotipadas y muy simplificadas, lo que refuerza la heteronormatividad.

Para comprobar las hipótesis se seleccionaron largometrajes que cumplieran los siguientes requisitos:

a) que su estreno hubiera tenido lugar durante los años 2017 y 2018 para poder conocer el panorama actual.

b) que provinieran de las grandes productoras del circuito comercial de Hollywood (The Walt Disney Company, Universal Pictures o Sony Pictures, entre otras).

c) que entraran dentro de la categoría de cine blockbuster, esto es, películas dirigidas a un público mayoritario (Marzal-Felici y Soler-Campillo, 2018) y con un gran presupuesto en su 
elaboración y publicidad, para ello, todas las películas debían contar con un presupuesto mínimo de 150 millones de dólares.

d) que durante la fase previa al estreno de la película, se hubiera promocionado la inclusión de personajes LGTB+.

Finalmente, la muestra quedó integrada por los siguientes cinco largometrajes, en cuyo resumen hemos incluido también el rol del personaje LGTB+:

- Black Panther (Marvel Studios, 2018): película que cuenta la historia de T'Challa, un príncipe africano que vuelve a Wakanda, un país avanzado social y tecnológicamente, para ser proclamado Rey con la ayuda de la soldado Okoye, personaje secundario y queer.

- Jurassic World: El reino caído (Universal Pictures, 2018): secuela de Jurassic World, narra la amenaza que pesa sobre los dinosaurios que quedan vivos en la Isla Nublar y los dilemas éticos a los que se enfrentan los personajes sobre si abocar a estos animales a la extinción o salvarlos, como pretenden los protagonistas Claire Dearing y Owen Grady, ayudados por la asistente lesbiana y personaje secundario Zia Rodríguez.

- La bella y la bestia (Walt Disney Pictures, 2017):_adaptación del clásico de Disney, desarrolla la historia de amor entre Bella, una joven soñadora, y Bestia, un joven sobre el que pesa una maldición. LeFou es el sirviente gay enamorado de su señor, Gastón, anti-héroe y enemigo de Bella y Bestia.

- Star Wars: Los últimos Jedi (Lucasfilm, 2017): película de la saga de Star Wars que versa sobre las vicisitudes de la resistencia, liderada por la General Leia Organa, y en donde cobra protagonismo la misión salvífica del capitán Poe Dameron, quien tiene importantes diferencias con la vicealmirante Holdo, personaje secundario y bisexual.

- Thor: Ragnarok (Marvel Studios, 2017):_narra la historia del súper-héroe_Thor y su misión de salvar el planeta Asgard de la destrucción por parte de las fuerzas del mal. Valquiria, mujer bisexual y personaje secundario, aunque en un principio obstaculiza dicha misión, finalmente será reconvertida por Thor y se unirá a la causa del bien.

La metodología se basa, en primer lugar, en un análisis de la promoción previa al estreno de las películas a través de entrevistas, declaraciones por parte del reparto, equipo y productora y las repercusiones sociales y comerciales de estas declaraciones y, en segundo lugar, en un análisis crítico del discurso. Como ya hemos planteado, el ACD es una investigación analítica sobre el discurso que estudia primariamente la forma en que el abuso de poder social, el dominio y la desigualdad son practicados, reproducidos, y ocasionalmente combatidos, por los textos y el habla en el contexto social y político (Van Dijk en García-Jiménez, Rodrigo-Alsina y Pineda, 2015).

El análisis crítico del discurso parte de un problema social; en el caso de nuestro estudio, el elemento sometible a crítica y discusión es la construcción mediática estereotipada de la diversidad sexual o, directamente, su ausencia del imaginario cinematográfico de los blockbuster. En general, las minorías sexuales LGTB+ no participan en la construcción del discurso y son presentadas a partir de (y frente a) los rasgos de las mayorías culturales heterosexuales.

Para ello, hemos articulado nuestro análisis en dos niveles, que son:

1. Nivel macro: discurso dominante, entendido como sistemas de ideas, que articula la película con respecto a la minoría LGTB+ a partir del análisis de los elementos presentes y ausentes. Es necesario que en este nivel atendamos a los topics, a cuáles son las ideas generales que articulan el discurso cinematográfico sobre la diversidad sexual. Se trata de los temas que proporcionan a los discursos coherencia global. Según Van Dijk (2003, p. 152), los temas representan el asunto "de que trata" el discurso, ya que en términos generales incluyen la información más importante de un discurso y explican la coherencia de los textos y las 
conversaciones. Los temas son "macroestructuras semánticas" derivadas de (micro) estructuras de significado o proposiciones particulares expresadas en el texto (García-Jiménez et al., 2015).

2. Nivel micro: aspectos más concretos del contenido analizado. Concretamente, nos hemos centrado en las siguientes cuestiones:

a. Lexicalización de los personajes: se analiza cómo son construidos los personajes LGTB + , cuál es la relación entre los personajes LGTB + y los personajes heterosexuales, cuáles los estereotipos, si se produce la estrategia del nosotros (ingroup heterosexual) frente al ellos (out-group homosexual) y la construcción de la sexualidad (presente/ausente).

b. Estructuras proposicionales: Se basa en la asignación de roles a ciertos actores y sujetos (Johnson, Sonnett, Dolan, Reppen y Johnson, 2010, p. 248; Pineda, GarcíaJiménez y Rodrigo-Alsina, 2016). El propositional framing asigna roles a actores y puede establecer una relación dicotómica entre nosotros y ellos (Johnson, Sonnett, Dolan, Reppen y Johnson, 2010, p. 252). Un aspecto interesante de las estructuras proposicionales son los roles semánticos (semantic roles) de los argumentos proposicionales, tales como agent, patient, objetc, etc. Si un grupo social es mostrado como agente responsable de actos negativos, este propositional framing se añade al retrato negativo de dicho grupo. Así, la agentividad (agency) se entiende como el rol temático del sujeto que ejecuta la acción. Esta cuestión está relacionada con el concepto de polarización conceptual, destacar aspectos positivos del nosotros frente a aspectos negativos del ellos.

c. Focus: punto de vista privilegiado en el discurso. Se relaciona con la idea de foreground o background información, proposiciones, o partes de proposiciones (Van Dijk, 1995, p. 263). El focus puede privilegiar un punto de vista en el discurso, mientras se encubre otro.

\section{Resultados}

\subsection{Resultados del análisis de las entrevistas y elementos promocionales previos al estreno del blockbuster}

En los cinco largometrajes analizados se repite un patrón común: la publicidad sobre la inclusión de historias y/o personajes LGTB+ durante la promoción del blockbuster (estrategia que hemos denominado pinkwashing), pero una posterior eliminación en el montaje final de aquellas escenas que hicieran referencia explícita a ello (práctica denominada queerbaiting) (ver tabla 1. Construcción mediática de la diversidad sexual (DS) en el cine blockbuster de Hollywood (2017-2018)).

En el caso de La bella y la bestia (2017), previo a su estreno, el director de la película, Bill Condon, afirmó que la homosexualidad de uno de los personajes de la película, LeFou, contaría con una trama secundaria y un final feliz para ello (Attitude, 2017; BBC News, 2017). El director señaló que "al final el personaje tiene su recompensa, pero no quiero revelar nada" (BBC News, 2017) y que su intención con ello era abrir nuevos caminos a la visibilidad LGTB+ (Attitude, 2017). La productora de la película, The Walt Disney Company, aseguró con orgullo que con la inclusión de este personaje se cumplía el "primer momento exclusivamente gay" de la historia en una película de la compañía (BBC News, 2017). Además, medios internacionales como Attitude (2017) afirmaron que: 
Al representar la atracción hacia personas del mismo sexo en esta escena breve pero explícitamente gay, el estudio está enviando un mensaje de que esto es normal y natural, y este es un mensaje que se escuchará en todos los países del mundo, incluso en los países donde aún es socialmente inaceptable o incluso ilegal ser gay. (2017)

A pesar de ello, con el anuncio de la inclusión de este personaje, en redes sociales como Twitter aparecieron comentarios homofóbicos como "supongo que no voy a llevar a los niños a ver esta película" y "dejad a los niños ser niños", acusando a la productora de "confundir a los niños" y de "arruinar una perfecta historia de amor" (Attitude, 2017). Además, países como Malasia decidieron censurar y eliminar cuatro minutos y medio de escenas del personaje de LeFou. Las autoridades del país consideraron que "es una escena inapropiada ya que muchos niños irán a ver la película" (Attitude, 2017). En Malasia solo es posible la representación LGTB+ en los medios si estos personajes "se arrepienten" o son mostrados con una imagen negativa (Attitude, 2017). Junto a ello, países que tradicionalmente no han protegido los derechos del colectivo LGTB+ como Rusia, que posee leyes "antipropaganda homosexual", decidieron obligar a los menores de 16 años a ver esta película acompañados de un adulto (Attitude, 2017).

Por otro lado, en el estado de Alabama (Estados Unidos), el propietario de los cines Henagar DriveIn decidió no proyectar la película en sus cines considerando que no sería una película adecuada "si no podemos llevar a nuestra nieta de 11 años y a un nieto de 8 años pues compromete lo que se enseña en la Biblia" (Redondo, 2017).

En este mismo sentido, el personaje de Zia Rodríguez en Jurassic World: El reino caído se identificaba como lesbiana durante una escena que fue eliminada en la versión final mostrada en los cines. La misma actriz justificó la eliminación de esa breve escena para "ahorrar tiempo" (Caviaro, 2018). En el caso de Valquiria en Thor: Ragnarok fue presentado como "el primer personaje gay en una producción de Marvel” (De Miguel, 2017). Sin embargo, esta escena también fue eliminada de la película. La actriz encargada de interpretar a Valquiria en el largometraje, Tessa Thompson, manifestaba que "sí, Val es bisexual en el cómic, y yo me mantuve fiel a esa representación. Pero no hay referencia explícita a su sexualidad en Thor: Ragnarok" (García-Martes, 2017). Los productores de la película indicaron como motivo para la eliminación de la bisexualidad de Valquiria que "podía distraer al público de la verdadera trama" (Ayuso y Belinchón, 2018).

Todos estos patrones se repiten en el resto de los largometrajes analizados, como en los personajes de Okoye y Ayo, que interpretan a dos guerreras abiertamente queer en los cómics en los que se basa el largometraje, Black Panther. Durante una versión mostrada en un pase previo al estreno de la película, se podía observar una escena de flirteo entre estas dos mujeres. Esta fue suprimida de la versión final que llegó a los cines, a lo que Joe Robert Cole, coguionista de la película, añadió: "Solamente sé que no era algo importante en términos de la historia. Tampoco queríamos extendernos con eso" (Cinemanía, 2018; Moreno, 2018). En relación a la eliminación de la trama de la película, los creadores de cómics de Black Panther afirmaron que:

Incluso con los progresos que se han hecho, se les dice a algunos colectivos marginados que

tienen que esperar, que todavía no es su momento, que primero hay que hacer otras cosas. 
También se nos dice que quizá pedimos mucho y que deberíamos estar agradecidos por los progresos que se han hecho. (Cinemanía, 2018)

Finalmente, en el caso del personaje de Amilyn Holdo, esta fue presentada como bisexual durante una novela previa al estreno de Los últimos Jedi (Europapress, 2017) y se confirmaba como el primer personaje LGTB+ en una película de la saga Star Wars (Moreno, 2017), pero no apareció mención explícita a ello en ningún momento durante el largometraje. Solamente de forma implícita en un momento de la película puede interpretarse su posible enamoramiento de la princesa Leia.

Con respecto al contexto global de producción de estos largometrajes, la mayoría de ellos contaron con nominaciones a premios reconocidos internacionalmente. Es el caso de Black Panther, nominada a siete estatuillas, incluyendo mejor película y mejor banda sonora en los Óscar de 2019. Por su parte, Star Wars: Los últimos Jedi fue nominada a mejor banda sonora, mejor sonido, mejor edición de sonido y mejores efectos visuales en los Óscar de 2018 y a mejor sonido y mejores efectos visuales en los premios BAFTA 2018. También La bella y la bestia (2017) obtuvo dos nominaciones a mejor diseño de producción y mejor diseño de vestuario tanto en los premios Óscar como en los premios BAFTA en 2018. Thor: Ragnarok, por su parte, obtuvo diversas nominaciones en certámenes como los Premios de la Crítica Cinematográfica o los Premios Empire.

\subsection{Resultados a nivel macro: los discursos sobre los colectivos LGTB+}

Los resultados muestran tres discursos como ideas organizadoras con respecto a la diversidad sexual (DS) en los largometrajes:

1) La diversidad sexual como parodia:

En este discurso, la diversidad sexual aparece construida como una parodia, con una clara vis cómica y, en ocasiones, incluso como un juego. Lo encontramos en la película La bella y la bestia en la que se muestra la diversidad sexual de manera implícita (nunca explícita) (ver tabla 1) y en la que LeFou es un personaje afeminado y bufón que articula esta visión sobre lo LGTB+, como confirman también recientes investigaciones sobre el mismo personaje (Contreras-Pulido, Guzmán-Franco y Vizcaíno-Verdú, 2020). Esta representación sustenta el discurso de una DS cómica en detrimento de una posibilidad real de declaración afectiva (Peña-Zerpa, 2013), anulando cualquier opción de que la trama LGTB+ pueda ir más allá del humor y derivar en una relación sexual o amorosa entre los personajes.

2) La diversidad sexual como aflicción y tragedia:

Este discurso asocia la diversidad sexual a la tragedia y al trauma, en contraposición a la heterosexualidad asociada a la victoria, la buena suerte, la estabilidad y fortaleza psicológicas. Es el discurso construido a partir de Valquiria, de la película Thor: Ragnarok, presentada como un personaje rudo y continuamente alcoholizado, como veremos en el análisis micro, debido al asesinato de su pareja en una batalla del pasado: "Vamos a morir, así que a beber". A pesar de que Thor es una película de acción marcada por la violencia, solamente el personaje LGTB+ está atormentado y trata de superar el dolor del pasado y la muerte de su novia mediante el alcohol, un contexto de tragedia que, tal y como hemos visto en el apartado 1.3., reproduce uno de los estereotipos clásicos con las que se ha asociado a las minorías sexuales (Melero, 2014). 
Este discurso también estaría presente en la película Star Wars: Los últimos Jedi, donde la vicealmirante Holdo está construida mediante uno de los estereotipos clásicos de los personajes LGTB+ en el cine, el final trágico (Melero, 2014). En esta ocasión, el personaje, tras fallar en su labor de liderazgo, se sacrifica y muere para salvar a toda la resistencia que está escapando a otro planeta para sobrevivir

3) La diversidad sexual ausente:

Hay 2 películas en las que, como hemos visto en el apartado 3.1 y queda recogido en la tabla 1, se ha eliminado cualquier mención explícita o implícita a la diversidad sexual. De esta forma, Black Panther y Jurassic World: El reino caido plantean un discurso en el que la realidad social es y solamente puede ser heterosexual, no hay espacio para otras orientaciones sexuales, que ni tan siquiera son sugeridas.

\subsection{Resultados a nivel micro: la construcción de los personajes LGTB+, sus contextos y perspectivas}

\subsubsection{Lexicalización}

En general, puede decirse que la sexualidad de los personajes heterosexuales es mostrada abiertamente (como Owen y Claire en Jurassic World; Bella y Bestia; Finn y Rose en Star Wars; o Jane y Thor en Thor), mientras que la de los colectivos LGTB+ se encuentra ausente de manera explícita en todas las películas y de forma implícita en hasta 2 de los 5 largometrajes analizados (ver tabla 1). Solo implícitamente aparece la diversidad sexual en La bella y la bestia, Thor y Star Wars. La mayor visibilidad de la heterosexualidad normaliza y legitima esta orientación, mientras que relega a los márgenes de lo social o directamente niega las identidades LGBT+.

Esta cuestión que estamos apuntando queda reflejada en el personaje de LeFou, en La bella y la bestia, donde a pesar de la simbología y elementos (afectivos, sexuales, gestuales, etc.) que nos permiten identificarlo como un personaje homosexual (“¿Para qué ella si ya estamos nosotros?” -en una conversación con Gastón), nunca se produce una mención o declaración sobre ello. Es posible hablar entonces de la aparición del estereotipo del homosexual omitido (Peña-Zerpa, 2013), es decir, una homosexualidad latente que no se manifiesta explícitamente durante la película. También encontramos aquí el estereotipo del cine clásico de Hollywood del gay reprimido (Peña-Zerpa, 2013). Asimismo, la polémica escena homosexual en La bella y la bestia, cuestionada por los sectores conservadores que la acusaban de ser perjudicial para los niños y alabada por la productora considerándola rompedora y novedosa en la historia del cine, se produce durante un total de cuatro segundos en los que, durante un baile real en el palacio, LeFou realiza un cambio de pareja y baila con el personaje masculino que en una escena anterior había aparecido de forma cómica vestido de mujer.

Esta homosexualidad latente también aparece en el personaje de Holdo en Star Wars, al que se le insinúa una adoración y posible enamoramiento hacia la princesa Leia: "Fue usted quien me enseñó", mientras ambas se aprietan las manos mutuamente conmovidas y con los ojos llorosos.

Los personajes LGTB son construidos a partir de la estereotipación y, mientras que los hombres son parodiados con rasgos del imaginario social sobre femineidad, a las mujeres se les atribuyen rasgos de hipermasculinidad, estereotipos clásicos con los que históricamente se han construido las identidades sexuales minoritarias (Peña-Zerpa, 2013). Es el caso de LeFou en La bella y la bestia, que representa al personaje homosexual enamorado en secreto de su señor heterosexual, y que debe 
sufrir en silencio por su amor no correspondido mientras observa cómo su enamorado pretende y tiene relaciones con otras personas. LeFou aparece como un homosexual afeminado (Peña-Zerpa, 2013), cómico y bufón de Gastón (el anti-héroe), con ademanes, gestos, expresiones y formas de actuar características y típicas de la femineidad del cine clásico de Hollywood (Kaplan, 1998), parodiando el rol de damisela débil que intenta conquistar al varón masculino de la película. También en La bella y la bestia aparece una estereotipación de la transexualidad y el travestismo con fines humorísticos y caricaturescos. Esto ocurre durante la escena en la que un personaje del bando de Gastón es vestido de mujer como forma de humillación, a lo que él responde con gestos paródicos de amaneramiento femenino mientras un personaje comenta: “¡Monísimos, corred, sed libres!”.

Por otro lado, los personajes femeninos son mostrados con los estereotipos tradicionales de la cinematografía asociados a la masculinidad (García-Toca y Nader-Carreta, 2009), representándolos con el estereotipo establecido en el imaginario sociocultural de "lesbiana masculina" (González de Garay, 2013). Estos personajes son representados con rasgos de hipermasculinización, propios de los personajes masculinos tradicionales del cine de Hollywood, tal y como son contar con una gran agresividad, destreza y fuerza física, un carácter rudo, serio y malhumorado y con dificultades por sentir empatía o expresar sentimientos, rasgos todos ellos propios de la masculinidad hegemónica (Kaplan et al., 2017). Los personajes femeninos poseen siempre una actitud de ataque, en el caso de Valquiria, con una daga que muestra a la menor ocasión para defenderse, disparando o lanzando botellas de cristal contra los demás. Valquiria, si bien en la primera parte del largometraje se mueve por sus propios intereses, por supervivencia y por dinero y se muestra con dificultad para mostrar sentimientos ("Yo no ayudo a nadie"), en la segunda parte, una vez ha sido reconvertida por el súperhéroe Thor a la causa de la justicia, la finalidad del personaje es la venganza por el asesinato de su pareja: "Prefiero morir hundiendo mi espada en el corazón de una arpía asesina". Mientras que en el caso de Zia en Jurassic World, ex infante de marina y con gran tendencia a la irascibilidad, es representada con discusiones y constantes reproches a sus compañeros de trabajo: "No dejes que tu mamá te compre la ropa", "Tranqui, es más fácil que mueras montando a caballo que en un avión" o "Franklin, cagueta, sube al avión". Igualmente, Okoye, en Black Panther es vestida con un traje sensual y con una peluca con pelo largo y rizado para infiltrarse y pasar desapercibida en una discoteca, mientras que se produce la siguiente conversación:

- "Esto será rápido y podré quitarme esta cosa ridícula de la cabeza.

- Te queda bien, tú muévela de lado a lado.

- ¿¡Qué?! Es una deshonra”.

Además, los personajes femeninos son mostrados con una personalidad autoritaria, como en el caso de las guerreras Okoye y Ayo en Black Panther: "Como rey, tu deber es...", "No diréis nada de este día", "Sirve a tu país", o en el de la vicealmirante Holdo, en Star Wars: Los últimos Jedi: "Quédese en su puesto y cumpla mis órdenes".

Estos clichés de hipermasculinización, propios de los guerreros y luchadores masculinos del cine cásico, además son manifestados abiertamente en los discursos de los otros personajes: en el caso de Zia, otro personaje le recrimina: "No tienes por qué insultarme cada vez que alguien te cabrea" y otro la define como: “¿Qué tía más borde!”. A Valquiria, por su parte, otro personaje se refiere a ella como: "Chica furiosa".

Por otro lado, el discurso de la homosexualidad como aflicción y tragedia (nivel macro) se articula en este nivel micro a partir del personaje de Valquiria en Thor. Su personalidad ruda, enfadada y constantemente alcoholizada se basa en su pasado trágico y es debida a que durante una batalla su pareja femenina fue asesinada. Durante la película se refieren a estos acontecimientos con eufemismos tal y como "el coste fue enorme". Sin embargo, a pesar de la ausencia de afectividad 
sexual, que solo es mostrada explícitamente en escenas eliminadas de la película, este personaje se encuentra paradójicamente sexualizado y otros se refieren a ella como "preciosa, fuerte y valiente".

Además, dentro de los rasgos encontrados del pinkwashing, en el que la sexualidad de los personajes es mencionada durante la promoción pero ocultada en el largometraje, aparece una clara unión de esta técnica con otra relacionada con el blanqueamiento aplicado a las características étnicas y raciales de los personajes, dentro del contexto del conocido como whitewashing. De esta forma, cuatro de los seis personajes LGTB+ analizados pertenecen también a grupos de población no caucásicos, como es el caso de Zia en Star Wars, asiática, Okoye y Ayo en Black Panther, afroamericanas, y Valquiria en Thor, latina.

En definitiva, en la lexicalización de los personajes LGTB+ no se muestran elementos de carácter afectivo ni hay repercusión por parte de estos u otros, por lo estas películas se basan en una homosexualidad encubierta, entendible por los espectadores solamente en algunos de estos largometrajes, pero nunca explícita, mientras que el resto de personajes heterosexuales cuentan abiertamente con momentos de complicidad y afectividad (caricias, besos, etc.). Por lo tanto, una homosexualidad oculta convertida en ellos, sobre los que no es posible hablar, frente a una heterosexualidad visible, normalizada, articuladora de la trama: el nosotros. A continuación queda desarrollada esta cuestión.

\subsubsection{Estructuras proposicionales y focus}

En general, las acciones llevadas a cabo por los personajes LGTB+ son de carácter cómico, negativo o simplemente intranscendente, un recurso, en definitiva, para enfatizar las acciones positivas que hacen avanzar la acción y que son llevadas a cabo por los héroes/heroínas heterosexuales. Los personajes LGTB+ se presentan así como contraste o antítesis de los heterosexuales, conformando un claro ellos homosexual frente a un nosotros heterosexual.

Esta caricaturización aparece en el personaje de LeFou, en La bella y la bestia, que está representado con todas las características de un personaje humorístico (Lorenzo, 2005) al servicio del villano, Gastón, y que cuenta con la función de provocar la risa en el espectador. El personaje se muestra a sí mismo como analfabeto: "Y su nombre es G-A-S, creo que ahora viene una T, pero resulta que analfabeto soy", y sirve de alivio cómico del largometraje en escenas como en la que es utilizado por Gastón para recibir los golpes de boxeo por parte de otro personaje. LeFou es inculto, borde ("olvídense de él, señoritas" a unas chicas del pueblo), mentiroso, burdo, superficial, cobarde y sometido a Gastón, el anti-héroe. En su rol de sirviente enamorado de Gastón, Le Fou miente y adula y funciona junto con su amo como antítesis de los protagonistas Bella y Bestia, quienes son cultos, sensibles, verdaderos y valientes y construidos mediante acciones positivas (dialogan, leen, se enamoran, etc.).

Las tramas asociadas a LeFou tienen un claro carácter secundario y su rol no favorece el avance de la acción ni cuenta con una importancia real para la historia, mientras el resto de los personajes heterosexuales, excepto el villano, muestran un arco dramático y son definidos mediante imágenes positivas: la amabilidad, el coraje, la valentía, la ternura o la bondad, entre otras. Así, de forma dicotómica, estos personajes heterosexuales realizan las acciones positivas que permiten acabar con el "final feliz" del cuento frente a LeFou, que por el intento de contentar a su compañero, es integrado en un propositional framing de acciones cómicas y negativas.

Estos propositional framing negativos también son mostrados en Valquiria (película Thor), violenta y agresiva, en cuya presentación el personaje aparece bebiendo y al bajar de un avión cae por la 
rampilla debido a su estado alcoholizado. Valquiria es un personaje atormentado, sin sentido de la ética o la justicia y necesita que Thor, el héroe humano, valiente y que expresa emociones, la salve de su solipismo. Mientras que este último lucha por salvar a su pueblo, dialoga o perdona, Valquiria bebe, ataca o engaña y sus acciones son siempre violentas hasta que es redimida por Thor.

Esta contraposición del nosotros frente al ellos también es un recurso utilizado en Black Panther y Star Wars. En la primera, la soldado queer Oyoke no muestra compasión, le cuesta mostrar sus sentimientos y se rige por las estrictas normas militares de su país y no por la ética, lo que contrasta con el personaje principal, el rey $\mathrm{T}^{\prime}$ Challa, compasivo, humano y enamorado de Nakía, quien tiene un marcado sentido de la justicia social hacia los más desfavorecidos. En Star Wars el capitán Poe Dameron es una persona emotiva y humana, a quien no le importa saltarse las normas para proteger a sus compañeros/as, lo que queda enfatizado por el rol de la vicealmirante Holdo, quien se muestra rígida, intransigente y está marcada por las jerarquías militares intergalácticas.

Las acciones negativas desarrolladas por los personajes LGTB + necesitan de una redención final pues deben enmendarse de sus errores del pasado. Sucede con Valquiria, en Thor, quien finalmente se une a la causa de la justicia; Okoye, en Black Panther, quien se arrepiente de su falta de compasión hacia el rey T'Challa; Le Fou, en La bella y la bestia, quien finalmente lucha a favor de Bella y Bestia; la vicealmirante Holdo, en Star Wars, quien debe sacrificar su propia vida para compensar sus errores al frente de la resistencia; o Zia Rodríguez, en Jurassic World, quien finalmente muestra su compasión con la niña Maisie. Los héroes y heroínas heterosexuales no deben redimirse pues sus acciones son principalmente positivas.

Sobre el focus, el punto de vista privilegiado en el discurso es la heteronormatividad, pues los personajes LGTB + se encuentran definidos y caracterizados a partir de los protagonistas heterosexuales y supeditados a ellos. Esto implica que ninguno de los personajes LGTB + es construido de forma independiente y en igualdad de condiciones que los heterosexuales.

Este punto de vista privilegiado se observa en personajes como el de Ayo y Okoye en Black Panther, que se encuentran subordinados al resto de personajes principales heterosexuales protagonistas, como reflejan las siguientes oraciones: "Mi príncipe, nos estamos acercando" (mostrando actitudes de sumisión y reverencia) o "Sí, mi general", lo que remite a la jerarquización propia de los sistemas militares. Ambos personajes dedican su vida por completo a la protección de su rey y su pueblo y renuncian a tener un desarrollo vital propio e independiente: "Soy leal a ese trono, sin importar quién se siente en él". Las mismas características se repiten en el personaje de Valquiria, en la película sobre Thor, con expresiones como: “¿Qué podemos hacer?”, “-¿Vamos? -Después de ti” o "Tu trono", reverenciando al personaje de Thor (el rey). Estas expresiones ponen en evidencia la falta de iniciativa del personaje, presentado con una cierta pasividad y, por tanto, desagentivizado, pues no es la responsable principal y directo de las distintas acciones llevadas a cabo.

En el caso de LeFou en La bella y la bestia, de igual forma, se muestra como un personaje supeditado a Gastón, siempre apegado a él, aceptando sus órdenes y siguiendo fielmente sus movimientos. Se produce así de forma metafórica un contraste entre la homosexualidad latente de LeFou y su intento de atraer o llegar a ser como el personaje de Gastón. Este último está caracterizado y basado en el ideal de masculinidad heterosexual tradicional cinematográfico (Laguarda, 2006): varón, blanco, musculado, atractivo, pícaro, rudo, viril, egocéntrico, que siempre consigue sus objetivos ("Serás mi esposa, ya lo verás”, en conversación con el personaje de Bella) y que es el objeto de deseo de las mujeres del pueblo. Una masculinidad hegemónica que es el ideal a seguir en contraste con una homosexualidad parodiada e irrelevante. Esta dualidad es característica 
de la crítica realizada a la sociedad heteropatriarcal desde la teoría queer (Butler, 1990; Foucault, 2002, 2005, 2010).

Asimismo, el único rol del personaje es el de conseguir la aprobación de Gastón mediante la servidumbre y el apoyo a sus comportamientos negativos y se observan elementos que sugieren una enfermiza dependencia emocional. Con relación a ello, se produce un sometimiento y maltrato de este personaje hacia LeFou mostrado en diferentes situaciones, de manera verbal: "¿Quieres ser el siguiente? ¡Tráeme mi caballo!” y de forma física y cómica, cuando LeFou canta que "en la lucha te clava sus dientes, Gastón” y se muestra una mordedura en el estómago.

Además, el personaje de Gastón niega las evidencias sobre la orientación sexual de su compañero: "Ah, LeFou, eres el mejor, ¿cómo es que aún ninguna chica te ha pescado?", lo que implica la existencia en la película de la presunción de heterosexualidad de todos los personajes, elemento clave de la teoría de la "heterosexualidad obligatoria" (Rich, 1996). Esta teoría asocia a instituciones como los medios de comunicación con la suposición y socialización en la heterosexualidad como orientación normalizada y naturalizada, excluyendo al resto de orientaciones sexuales diversas.

En definitiva, tal y como hemos visto, la hipermasculinización de los personajes femeninos y la feminización de los masculinos viene a reforzar una perspectiva heteropatriarcal (focus), en la que la mayoría heterosexual mira a la minoría LGTB + a partir de prejuicios y estereotipos. La tabla 1 resume los principales resultados del análisis desarrollado en los apartados 3.1 y 3.2.

Tabla 1. Construcción mediática de la diversidad sexual (DS) en el cine blockbuster de Hollywood (2017-2018).

\begin{tabular}{|c|c|c|c|c|c|c|c|c|c|}
\hline \multicolumn{2}{|c|}{ Caracterización } & \multirow{2}{*}{$\begin{array}{c}\text { Nivel } \\
\text { Macro } \\
\\
\text { Discurso }\end{array}$} & \multicolumn{7}{|c|}{ Nivel micro } \\
\hline $\begin{array}{l}\text { Película } \\
\text { Personaje } \\
\text { Orientación } \\
\text { Género }\end{array}$ & $\begin{array}{l}\text { Pinkwas } \\
\quad \text { hing }\end{array}$ & & Queerbating & $\begin{array}{c}\text { DS } \\
\text { explícita }\end{array}$ & $\begin{array}{c}\text { DS } \\
\text { implícita }\end{array}$ & $\begin{array}{l}\text { Nosotros } \\
\text { frente a } \\
\text { Ellos }\end{array}$ & $\begin{array}{l}\text { Focus: } \\
\text { Heteronorm } \\
\text { atividad }\end{array}$ & Estereotipos & $\begin{array}{l}\text { Redención } \\
\text { final }\end{array}$ \\
\hline $\begin{array}{c}\text { Thor } \\
\text { Valquiria } \\
\text { Bisexualidad } \\
\text { Mujer } \\
\end{array}$ & $\sqrt{ }$ & $\begin{array}{l}\text { DS como } \\
\text { aflicción y } \\
\text { tragedia }\end{array}$ & $\sqrt{ }$ & $\mathrm{X}$ & $\sqrt{ }$ & $\sqrt{ }$ & $\sqrt{ }$ & $\begin{array}{c}\text { mujer } \\
\text { masculina } \\
\text { inestabilidad } \\
\text { mental } \\
\end{array}$ & $\sqrt{ }$ \\
\hline $\begin{array}{c}\text { La Bella y la } \\
\text { Bestia } \\
\text { Le Fou } \\
\text { Gay } \\
\text { Hombre }\end{array}$ & $\sqrt{ }$ & $\begin{array}{c}\text { DS como } \\
\text { parodia }\end{array}$ & $\sqrt{ }$ & $\mathrm{X}$ & $\sqrt{ }$ & $\sqrt{ }$ & $\sqrt{ }$ & $\begin{array}{l}\text { hombre } \\
\text { femenino gay } \\
\text { reprimido }\end{array}$ & $\sqrt{ }$ \\
\hline $\begin{array}{c}\text { Black Panther } \\
\text { Okoye } \\
\text { Queer } \\
\text { Mujer }\end{array}$ & $\sqrt{ }$ & DS ausente & $\sqrt{ }$ & $\mathrm{X}$ & $\mathrm{X}$ & $\sqrt{ }$ & $\sqrt{ }$ & $\begin{array}{l}\text { mujer } \\
\text { masculina }\end{array}$ & $\sqrt{ }$ \\
\hline $\begin{array}{c}\text { Star Wars } \\
\text { A. Holdo } \\
\text { Bisexualidad } \\
\text { Mujer } \\
\end{array}$ & $\sqrt{ }$ & $\begin{array}{l}\text { DS como } \\
\text { aflicción y } \\
\text { tragedia }\end{array}$ & $\sqrt{ }$ & $\mathrm{X}$ & $\sqrt{ }$ & $\sqrt{ }$ & $\sqrt{ }$ & $\begin{array}{c}\text { mujer } \\
\text { masculina } \\
\text { final trágico }\end{array}$ & $\sqrt{ }$ \\
\hline $\begin{array}{c}\text { Jurassic } \\
\text { World } \\
\text { Z.Rodríguez } \\
\text { Lesbiana } \\
\text { Mujer }\end{array}$ & $\sqrt{ }$ & DS ausente & $\sqrt{ }$ & $\mathrm{X}$ & $\mathrm{X}$ & $\mathrm{X}$ & $\sqrt{ }$ & $\begin{array}{l}\text { mujer } \\
\text { masculina }\end{array}$ & $\sqrt{ }$ \\
\hline
\end{tabular}

Fuente: elaboración propia. 


\section{Discusión}

Partiendo de los objetivos propuestos en la investigación, es posible inferir el uso del pinkwashing en los recientes largometrajes blockbusters analizados de Hollywood. Esta técnica es utilizada por las productoras durante la promoción de las películas para publicitar que se ha producido uno de los primeros blockbusters destinados a un público mayoritario con personajes y/o tramas LGTB+ ("la primera película de Marvel en incluir un personaje homosexual"). Esta publicidad, además, les supone un blanqueamiento de su imagen al presentarse como majors progresistas. Sin embargo, ante el peligro de posibles pérdidas económicas por el boicot del público más conservador dados los altos costes económicos de producción, se produce una posterior eliminación de estas tramas en la versión final de la película. Así, para atraer al público LGBT+, se utiliza la técnica del queerbaiting, en la que se sugiere una posible trama amorosa mediante subtextos homoeróticos (LeFou y Gastón en $L a$ bella y la bestia) que nunca llega a producirse de forma explícita.

Por lo tanto, el pinkwashing y el queerbaiting son elementos de marketing utilizados en los blockbuster como reclamo publicitario y mejora de imagen, sin que llegue a producirse en estos largometrajes una construcción real, positiva y normalizada de la diversidad sexual, lo que confirma la primera hipótesis planteada en la investigación. De esta forma, enlazando con la revisión bibliográfica, estas películas siguen utilizando, al igual que desde el inicio de la censura cinematográfica, escenas solo interpretables como LGTB + a través de subtextos, pero no explícitamente, y evitan los elementos afectivos y sexuales.

Por otro lado, como ya adelantó el informe GLAAD de 2018, se confirma el uso de una tercera técnica, el whitewashing. Así, ante las tradicionales críticas a Hollywood por la escasa inclusión de personas no caucásicas, se observa en la mayoría de estas películas una unión entre personajes LGTB + y de otras etnias no habituales en los blockbusters (asiáticos, africanos o latinos), mientras que los protagonistas siguen conservando la hegemonía heterosexual y blanca. Los colectivos LGTB+ son utilizados como personajes token, sin peso real en la trama, pero que sirven para justificar la supuesta inclusión promovida desde el largometraje.

Con respecto a la segunda hipótesis, el uso del análisis crítico del discurso (ACD) como técnica confirma la existencia de diversas características y elementos de desigualdad en los largometrajes. En primer lugar, los discursos sobre la diversidad sexual como comedia, tragedia o ausencia refuerzan en el imaginario colectivo los estereotipos con los que la mayoría hegemónica heterosexual "mira" y define a la minoría LGTB+. En segundo, en el nivel micro, hemos visto cómo la estereotipación de los personajes está basada en los mismos atributos usados durante décadas en el cine clásico de Hollywood: el de asociar a la mujer rasgos de violencia, competitividad o control emocional propios de la masculinidad hegemónica (Kaplan et al., 2017), como en el caso de Valquiria en Thor: Ragnarok; la idea del homosexual amanerado (LeFou en La bella y la bestia), o el final trágico de los personajes del colectivo (Holdo en Star Wars: Los últimos Jedi).

El análisis micro nos ha permitido ahondar en la polarización entre un grupo dominante heterosexual, el nosotros, frente a un grupo en minoría, excluido de la representación y que tiende a ser invisivilizado o mostrado mediante subtextos o eufemismos, el colectivo LGTB + o ellos. Además, el rol de estos personajes es secundario y en la mayoría de las ocasiones son utilizados como alivio cómico y son los personajes heterosexuales los que mediante la agentividad realizan las acciones positivas y los que favorecen el avance real de la trama. A ciertos personajes analizados igualmente se la añaden propositional framings negativos, como en el caso de LeFou al apoyar las acciones delictivas del personaje de Gastón. En el mismo sentido, el focus de la película privilegia el punto de vista heterosexual mientras que oculta o minimiza el resto de orientaciones, que se encuentran 
supeditadas a la heteronormatividad imperante, mostrando de nuevo la dicotomía entre el nosotros y el ellos y una presunción de heterosexualidad en todos los personajes. De esta forma, el análisis, además de encontrarse en concordancia con el marco teórico previo, confirma las dos hipótesis planteadas.

\section{Conclusiones}

Una vez analizados los resultados es posible concluir que las representaciones incluidas en el cine blockbuster siguen fomentando una visión distorsionada que asocia estereotipos negativos al colectivo LGTB+, cuya sexualidad aparece invisibilizada y no se presenta en igualdad de condiciones a la heterosexual. Este hecho es de especial gravedad si tenemos en cuenta las audiencias masivas de este tipo de películas y su importante rol en la socialización y educación en el ámbito infantil y familiar, como es el caso de las producciones de Walt Disney. Por lo tanto, este cine de Hollywood tiene por delante un reto de vital transcendencia para la inclusión, el pluralismo y la democracia: la visibilización y normalización de personajes del colectivo LGTB+. En este sentido, la ficción seriada se presenta como un modelo a seguir por su apuesta por la diversidad sexual normalizada en series como Orange is the new black (Netflix: 2013-Actualidad) o Star Trek: Discovery (CBS: 2017-Actualidad).

Además, se confirma la presencia de las técnicas pinkwashing y queerbaiting utilizadas con el objetivo de atraer a un potencial público favorable a la normalización de la diversidad sexual, sin que esto pueda suponer una pérdida económica por las presiones de las audiencias más conservadoras.

Como líneas de investigación futuras se proponen tres frentes: el análisis de un mayor número de largometrajes para comprobar la existencia de las técnicas de pinkwashing y queerbaiting asociadas a la heteronormatividad; el estudio del whitewashing; y extender el análisis crítico del discurso a otros largometrajes más allá de los blockbusters, con especial atención al cine de carácter más independiente o minoritario.

En conclusión, la visibilidad sin más no es suficiente, pues una construcción simbólica negativa y estereotipada no ayuda a la liberalización simbólica y normalización de las minorías, al contrario, refuerza la visión hegemónica sobre la sexualidad. De este modo, a la luz de lo recogido en este artículo, los blockbusters de Hollywood continúan fomentado un status quo basado en la heteronormatividad y la desigualdad, a pesar de las campañas de marketing "rosa" promovidas por la industria cinematográfica.

\section{Bibliografía}

Attitude (1 de marzo, 2017). World exclusive: 'Beauty and the Beast' set to make Disney history with gay character. Attitude. https://attitude.co.uk/article/world-exclusive-beauty-and-the-beastset-to-make-disney-history-with-gay-character-1/13725/

Attitude (2 de marzo, 2017). These daily mail comments prove why 'Beauty and the Beast's' gay character is so important. Attitude. https://attitude.co.uk/article/these-daily-mail-comments-provewhy-beauty-and-the-beasts-gay-character-is-so-important/13738/

Attitude (15 de marzo, 2017). Disney refuses to censor 'Beauty and the Beast' gay momento for Malaysia. Attitude. https://attitude.co.uk/article/disney-refuses-to-censor-beauty-and-the-beastgay-moment-for-malaysia/13835/ 
Attitude (15 de marzo, 2017). Watch the moment Alan Menken acknowledges 'Beauty and the Beast's gay subplot. Attitude. https://attitude.co.uk/article/watch-the-moment-alan-menkenacknowledges-beauty-and-the-beasts-gay-subplot/13836/

Ayuso, R. y Belinchón, G. (5 de julio, 2018). Hollywood no quiere personajes gais en sus superproducciones. El País. https://elpais.com/cultura/2018/07/05/actualidad/1530750324 764682.html

BBC News (3 de marzo, 2017). 'La bella y la bestia': un personaje gay, una escena de amor homosexual, un beso interracial... y es una película de Disney. $B B C$ News. https://www.bbc.com/mundo/noticias-39148300

Brennan, J. (2018). Queerbaiting: The 'playful'possibilities of homoeroticism. International Journal of Cultural Studies, 21(2), 189-206. https://doi.org/10.1177/1367877916631050

Butler, J. (1990). Gender trouble and the subversion of identity. Routledge.

Caviaro, J. L. (29 de julio, 2018). 'Jurassic World: El reino caído' es la última película de Hollywood que vuelve a meter en el armario a un personaje gay. Espinof. https://www.espinof.com/actores-yactrices/jurassic-world-reino-caido-ultima-pelicula-hollywood-que-vuelve-meter-armariopersonaje-gay

Cinemanía. (13 de febrero, 2018). ¿Ha eliminado Marvel una historia gay en 'Black Panther'? Cinemanía. https://www.cinemania.es/noticias/marvel-ha-eliminado-una-trama-gay-black-panther/

Contreras-Pulido, P., Guzmán-Franco, M. D. y Vizcaíno-Verdú, A. (2020). 'La Bella y la Bestia' y el movimiento LGTB en Disney: empoderamiento y activismo en YouTube. Área Abierta, 20(1), 75-93. https://doi.org/10.5209/arab.63129

De Miguel, A. (2 de noviembre, 2017). Así es la escena eliminada de 'Thor: Ragnarok' en la que Valquiria se declaraba abiertamente bisexual. Fotogramas. https://www.fotogramas.es/noticiascine/a19450515/escena-eliminada-thor-ragnarok-valkyria-bisexual/

Durán-Manso, V. (2014). El aula rompe con la censura en Hollywood: el caso de La calumnia. En Imatges de l'escola, imatge de l'educació: XXI Jornades d'Història de l'Educació. (pp. 19-37). Palma: Francesca Comas Rubí, Sara González Gómez, Xavier Motilla Salas, Bernat Sureda García (Coords.). https://dialnet.unirioja.es/servlet/articulo? codigo $=5497270$

Durán-Manso, V. (2016). La representación del deseo en el cine de Tennessee Williams: homosexualidad masculina frente al Código Hays. FEMERIS: Revista Multidisciplinar de Estudios de Género, 1(1/2), 58-73. http://dx.doi.org/10.20318/femeris.2016.3227

Echeverría, G. y Martín Maturana, J. (2015). Análisis crítico del discurso de políticas públicas en diversidad sexual en Chile. Universitas Psychologica, 14(4), 1485-1498. https://doi.org/10.11144/Javeriana.up14-4.acdp

Europapress (5 de septiembre, 2017) ¿Será Laura Dern el primer personaje LGTB de Star Wars? Europapress. $\quad$ https://www.europapress.es/cultura/cine-00128/noticia-sera-laura-dern-primerpersonaje-lgtb-star-wars-20170905122311.html 
Fairclough, N. (2008). El análisis crítico del discurso y la mercantilización del discurso público: las universidades. Discurso \& Sociedad, 2(1), 170-185.

https://dialnet.unirioja.es/servlet/articulo? codigo $=2547117$

Foucault, M. (2002). Historia de la sexualidad. Vol. 2: El uso de los placeres. Siglo XXI.

Foucault, M. (2005). Historia de la sexualidad. Vol. 1: La voluntad del saber. Siglo XXI.

Foucault, M. (2010). Historia de la sexualidad. Vol. 3: La inquietud de sí. Siglo XXI.

García-Jiménez, L., Rodrigo-Alsina, M. y Pineda, A. (2015). 'We Cannot Live in Our Own Neighborhood': An approach to the construction of intercultural communication in television news. En Miller, T. (Ed.). The Routledge companion to global popular culture (pp. 330-344). Routledge.

García-Martes, P. J. (24 de octubre, 2017). Marvel tiene su primer personaje LGTB en 'Thor: Ragnarok', pero de nada sirve si no se muestra. Ecartelera.

https://www.ecartelera.com/noticias/42895/marvel-primer-personaje-lgtb-thor-ragnarok-no-sirvemuestra/

García-Toca, I. y Nader-Carreta, F. (2009). Estereotipos masculinos en la relación de pareja. Enseñanza e Investigación en Psicología, 14(1). https://www.redalyc.org/pdf/292/29214103.pdf

GLAAD (Gays \& Lesbians Alliance Against Defamation) (2018). 2018 GLAAD Studio Responsibility Index. Los Ángeles: publicación online. https://www.glaad.org/sri/2018

González de Garay, B. (2013). El lesbianismo en las series de ficción televisiva españolas (Tesis Doctoral). Universidad Complutense de Madrid.

González, F. R. (2008). The feminine stereotype in gay characterization. Languages and Cultures in Contrast and Comparison, (175), 221. https://doi.org/10.1075/pbns.175.12gon

Johnson, K. A., Sonnett, J., Dolan, M. K., Reppen, R. y Johnson, L. (2010). Interjournalistic discourse about African Americans in television news coverage of Hurricane Katrina. Discourse \& Communication, 4(3), 243-261. https://doi.org/10.1177/1750481310373214

Kaplan, E. A. (1998). Las mujeres y el cine: a ambos lados de la cámara (Vol. 46). Universitat de València.

Kaplan, D., Rosenmann, A., \& Shuhendler, S. (2017). What about nontraditional masculinities? Toward a quantitative model of therapeutic new masculinity ideology. Men and Masculinities, 20(4), 393-426. https://doi.org/10.1177/1097184X16634797

Laguarda, P. (2006). Cine y estudios de género: Imagen, representación e ideología. Notas para un abordaje crítico. La Aljaba, (10), 141-156.

https://www.scienceopen.com/document?vid=f53507c6-c8fa-4ec9-9388-4b63cc0365de

Lorenzo, L. G. (2005). La construcción de un personaje: el gracioso (Vol. 147). Editorial Fundamentos. 
Marzal-Felici, J. y Soler-Campillo, M. (2018). El espectáculo del exceso. Representaciones de la crisis financiera de 2008 en el cine mainstream norteamericano. Revista Latina de Comunicación Social, (73), 89-114. https://doi.org/10.4185/RLCS-2018-1247

Melero, A. (2014). La representación de la homosexualidad en el cine de la dictadura franquista. ZER: Revista de Estudios de Comunicación, 19(36). https://www.ehu.eus/ojs/index.php/Zer/article/view/13500/0

Moreno, I. (4 de septiembre, 2017). Star Wars: Los Últimos Jedi tendrá al primer personaje LGTB de la saga. Areajugones. https://areajugones.sport.es/2017/09/04/star-wars-los-ultimos-jedi-tendra-alprimer-personaje-lgtb-de-la-saga/

Moreno, I. (12 de febrero, 2018). Marvel eliminó un romance homosexual del corte final de Black Panther. Areajugones. https://areajugones.sport.es/2018/02/12/marvel-elimino-un-romancehomosexual-del-corte-final-de-black-panther/

Pardo-Abril, N. G. (2007). Cómo hacer análisis crítico del discurso. Una perspectiva latinoamericana. Universidad Nacional de Colombia.

Pardo, A. (2011). Europa frente a Hollywood: breve síntesis histórica de una batalla económica y cultural. Doxa, 12, 39-59. https://recyt.fecyt.es/index.php/doxacom/article/view/35946

Peña-Zerpa, J. A. (2013). Estereotipos de hombres homosexuales en la gran pantalla (1970-1999). Razón y Palabra, 18(85). http://www.razonypalabra.org.mx/N/N85/M85/03_Pena_M85.pdf

Pineda, A., García-Jiménez, L., y Rodrigo-Alsina, M. (2016). 'I believe they felt attacked'. Discursive representation and construction of interculturality in Spanish news television. International Communication Gazette, 78(6), 585-605. https://doi.org/10.1177/1748048516640711

Puar, J. (2013). Rethinking homonationalism. International Journal of Middle East Studies, 45(2), 336-339. https://doi.org/10.1017/S002074381300007X

Redondo, M. (14 de marzo, 2017). Las primeras consecuencias del personaje gay en 'La Bella y la Bestia'. Hipertextual. https://hipertextual.com/2017/03/consecuencias-escena-gay-bella-bestia

Rich, A. (1996). Heterosexualidad obligatoria y existencia lesbiana. DUODA: Estudis de la Diferència Sexual, (10), 15-48. http://www.mpisano.cl/psn/wpcontent/uploads/2014/08/Heterosexualidad-obligatoria-y-existencia-lesbiana-Adrienne-Rich1980.pdf

Rubio-Alcover, R. (2007). Del blockbuster al high concept: los efectos digitales en el neoespectáculo hollywoodiense. En Gómez-Tarín, F. J. y Marzal-Felici, J. J. (Eds.), Metodologías de análisis del film (pp. 147-156). Edipo.

Smith, P. J. (2006). Cine, historia y homosexualidad: Far from Heaven (Lejos del cielo, 2002) de Todd Haynes y La mala educación (2004) de Almodóvar. Archivos de la Filmoteca, (54), 98. http://www.archivosdelafilmoteca.com/index.php/archivos/article/view/247

Spade, D. (2015). Normal life: Administrative violence, critical trans politics, and the limits of law. Duke University Press. 
Stakic, I. (2011). Homophobia and hate speech in Serbian public discourse: how nationalist myths and stereotypes influence prejudices against the LGBT minority. Equal Rights Review, (7), 44-65. https://www.equalrightstrust.org/ertdocumentbank/ERR7 isidora.pdf

Stecher, A. (2009). El análisis crítico del discurso como herramienta de investigación psicosocial del mundo del trabajo: discusiones desde América Latina. Universitas psychologica, 9(1), 93-107. https://doi.org/10.11144/Javeriana.upsy9-1.acdh

Van Dijk, T. A. (1995). Discourse semantics and ideology. Discourse \& society, 6(2), 243-289. http://www.discourses.org/OldArticles/Discourse\%20semantics\%20and\%20ideology.pdf

Van Dijk, T. (2002). El análisis crítico del discurso y el pensamiento social. Athenea Digital, (1), 1824. https://doi.org/10.5565/rev/athenead/v1n1.22

Van Dijk, T. (2003). La multidisciplinariedad del análisis crítico del discurso: un alegato a favor de la diversidad, en Wodak, R. \& Meyer. M. (Eds.), Métodos de análisis crítico del discurso (pp. 143-177). Gedisa.

Vasallo, B. (2013). PornoBurka: desventuras del Raval y otras f(r)icciones contemporáneas. Ediciones Cautivas.

\section{AUTORES:}

\section{Juan-José Sánchez-Soriano}

Juan-José Sánchez-Soriano (Murcia, 1990) es investigador predoctoral FPU por el Ministerio de Educación, Cultura y Deporte en la Universidad de Murcia, en la Facultad de Comunicación y Documentación. Premio Extraordinario Fin de Grado en Comunicación Audiovisual (Universidad de Murcia). Cuenta con varias publicaciones científicas a congresos internacionales, revistas y capítulos de libros en editoriales de prestigio. Vocal en la Asociación de Jóvenes investigadores de la Universidad de Murcia (AJIUM). Ha realizado estancias investigadoras, entre otras, en la University of Hull (Reino Unido) y en la Universitat Pompeu Fabra de Barcelona. Es miembro del grupo de investigación "Comunicación Social, Cultura y Tecnología" de la Universidad de Murcia y socio de la "Asociación Española de Investigación de la Comunicación". Cuenta con formación en nuevas tecnologías docentes y experiencia docente en el Grado en Periodismo en la asignatura Fundamentos de la Comunicación I. Sus líneas de investigación están centradas en la cinematografía, ficción seriada, estudios culturales, recepción en audiencias y estudios queer.

juanjose.sanchez4@um.es

Orcid ID: https://orcid.org/0000-0003-4371-0099

Google Scholar: https://scholar.google.es/citations?user=V-2mD8QAAAAJ\&hl=es

\section{Leonarda García-Jiménez}

Leonarda García-Jiménez (Murcia, 1979), Doctora en Comunicación, es profesora Titular en el área de Periodismo de la Universidad de Murcia y Affiliate Faculty en la Colorado State University. También ha impartido docencia e investigado en la Universidad del Norte (Colombia), Universidad de Sevilla y Autónoma de Barcelona (España), Universidad de Lugano (Suiza), en las mexicanas Autónoma de la Ciudad de México, Autónoma de Zacatecas y Colima y en la University of Colorado Boulder (EE.UU.), donde además completó su formación con una beca posdoctoral (Fundación Séneca, código de referencia 09395/PD/08). García-Jiménez ha publicado más de 45 investigaciones (libros, artículos y capítulos de libro) en sus líneas de especialización, entre las que se incluyen las 
teorías de la comunicación, la identidad y la interculturalidad. Estos trabajos han aparecido en revistas y editoriales de impacto SJR, JCR y SPI. Su último libro, En defensa de la comunicación (2019), ha sido publicado por la editorial Tirant Lo Blanch. Ha participado en más de 50 congresos especializados en comunicación, tiene 2 sexenios de investigación (2005-2010 y 2011-2016), ha sido investigadora principal en el proyecto financiado por la comisión europea CRICORM y ha formado parte de 3 proyectos $\mathrm{I}+\mathrm{D}+\mathrm{I}$ del Ministerio de Ciencia e Innovación del Gobierno de España. Actualmente_disfruta de una beca Leonardo BBVA 2019 con la que desarrolla el proyecto "feminizar las ciencias de la comunicación" para recuperar la memoria de destacadas mujeres investigadoras del siglo XX.

leonardagj@um.es

Índice H: 11

Orcid ID: https://orcid.org/0000-0002-5472-3314

Google Scholar: https://scholar.google.es/citations?user=f39SKIkAAAAJ\&hl=es 